\begin{tabular}{|c|l|}
\hline Title & $\begin{array}{l}\text { Synthesis of a , } \beta \text { - Unsaturated Carboxylic A cids by Nickel(II)-Catalyzed Electrochemical Carboxylation of V inyl } \\
\text { Bromides }\end{array}$ \\
\hline Author(s) & Kamekawa, Hisato; Kudoh, Hiroki; Senboku, Hisanori; Tokuda, Masao \\
\hline Citation & $\begin{array}{l}\text { Chemistry Letters, 26(9), 917-918 } \\
\text { https://doi.org/10.1246/1.1997.917 }\end{array}$ \\
\hline Issue Date & 1997-09-05 \\
\hline Doc URL & http://hdl.handle.net/2115/70908 \\
\hline Type & article \\
\hline File Information & cl.1997.917.pdf \\
\hline
\end{tabular}

Instructions for use 


\title{
Synthesis of $\alpha, \beta$-Unsaturated Carboxylic Acids by Nickel(II)-Catalyzed Electrochemical Carboxylation of Vinyl Bromides
}

\author{
Hisato Kamekawa, Hiroki Kudoh, Hisanori Senboku, and Masao Tokuda* \\ Division of Molecular Chemistry, Graduate School of Engineering, Hokkaido University, Sapporo 060
}

(Received May 30, 1997; CL-970408)

Electrochemical carboxylation of alkyl-substituted vinyl bromides (1)-1g) in the presence of $20 \mathrm{~mol} \%$ of $\mathrm{NiBr}_{2} \cdot$ bpy under an atmospheric pressure of carbon dioxide with a platinum cathode and a magnesium anode gave the corresponding $\alpha, \beta$ unsaturated carboxylic acids $(\mathbf{2 a - 2} \mathbf{g})$ in yields of $53-82 \%$.

Silvestri ${ }^{1,2}$ and Perichon ${ }^{3,4}$ both reported that electrochemical carboxylation of organic halides or carbonyl compounds readily occurs under an atmospheric pressure of carbon dioxide to give the corresponding carboxylic acids in high yields when a sacrificial anode, such as a magnesium or aluminum metal, is used in the electrolysis. We recently reported the regioselective synthesis of $\gamma$-substituted $\beta, \gamma$-unsaturated acids, ${ }^{5}$ allenic acids, ${ }^{6}$ and 3-methylene-4-pentenoic acid $^{7}$ by the electrochemical carboxylation of $\gamma$-substituted allylic halides, substituted propargylic halides, and 2-bromomethyl-1,4-dibromo-2-butene, respectively, using a magnesium anode. We also reported the efficient electrochemical carboxylation of aryl-substituted vinyl bromides to give the corresponding 2 -alkenoic acids in high yields. ${ }^{8}$ In the latter paper we showed that a precursor of ibuprofen, 2-( $p$-isobutylphenyl)propenoic acid, was readily prepared in a $93 \%$ yield. ${ }^{8}$ As part of our continuing studies on the electrochemical synthesis of useful carboxylic acids, we recently carried out the electrochemical carboxylation of alkyl-substituted vinyl bromides. In this paper, we report that the corresponding $\alpha, \beta$-unsaturated carboxylic acids are obtained in high yields when the electrochemical carboxylation of alkyl-substituted vinyl bromides is carried out in the presence of $\mathrm{Ni}$ (II) complex with a platinum cathode and a magnesium anode under an atmospheric pressure of carbon dioxide. None of aliphatic vinyl halides have been examined in electrochemical carboxylation using a sacrificial anode. The $\mathrm{Ni}(\mathrm{II})$-catalyzed electrochemical reaction of 2-bromo1-butene in the presence of atmospheric carbon dioxide has only been reported to give 2-ethylpropenoic acid in a 30\% yield. ${ }^{9}$

The present electrochemical method is useful for a synthesis of $\alpha, \beta$-unsaturated acids since they can readily be prepared in good yields in three steps from the corresponding alkenes. Conventional synthetic methods employ mostly aldehydes or ketones as a starting material. ${ }^{10}$

Electrochemical carboxylation of 1-bromocycloalkenes (1a1d $)^{11}$ under a slow stream of carbon dioxide gas with a platinum cathode and a magnesium anode gave 1-cycloalkene-1-carboxylic acids (2a-2d) in yields of $15-43 \%$ (Scheme 1). These electrochemical carboxylations were further studied under a variety of conditions in order to obtain higher yields of 2 . We found that the yield of $\mathbf{2 a}$ in the electrochemical carboxylation of $\mathbf{1 a}$ was extremely enhanced to $73 \%$ by the addition of $20 \mathrm{~mol} \%$ nickel(II) bromide-2,2'-bipyridine complex $\left(\mathrm{NiBr}_{2} \bullet\right.$ bpy) to the electrolysis solution. Electrolysis was carried out at $10 \mathrm{~mA} / \mathrm{cm}^{2}$ in a DMF solution containing $0.1 \mathrm{M} \mathrm{Bu}_{4} \mathrm{NBF}_{4}$ at $-10{ }^{\circ} \mathrm{C}$ under a slow stream

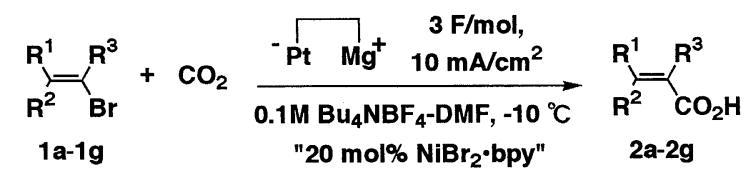

$\left(R^{1}, R^{2}, R^{3}=H\right.$ or Alkyl)

Scheme 1.

of carbon dioxide gas. An electricity of 3 Faradays per mol of $\mathbf{1 a}$ is required for efficient carboxylation. A one-compartment cell fitted with a platinum plate cathode $\left(2 \times 3 \mathrm{~cm}^{2}\right)$ and a magnesium rod anode $(3 \mathrm{~mm} \phi)$ was used for electrolysis.

Electrochemical carboxylation of various vinylic bromides (1a-1g) in the presence of $20 \mathrm{~mol} \%$ of $\mathrm{NiBr}_{2} \bullet$ bpy gave the

Table 1. Electrochemical carboxylation of alkyl-substituted vinyl bromides ${ }^{\text {a }}$

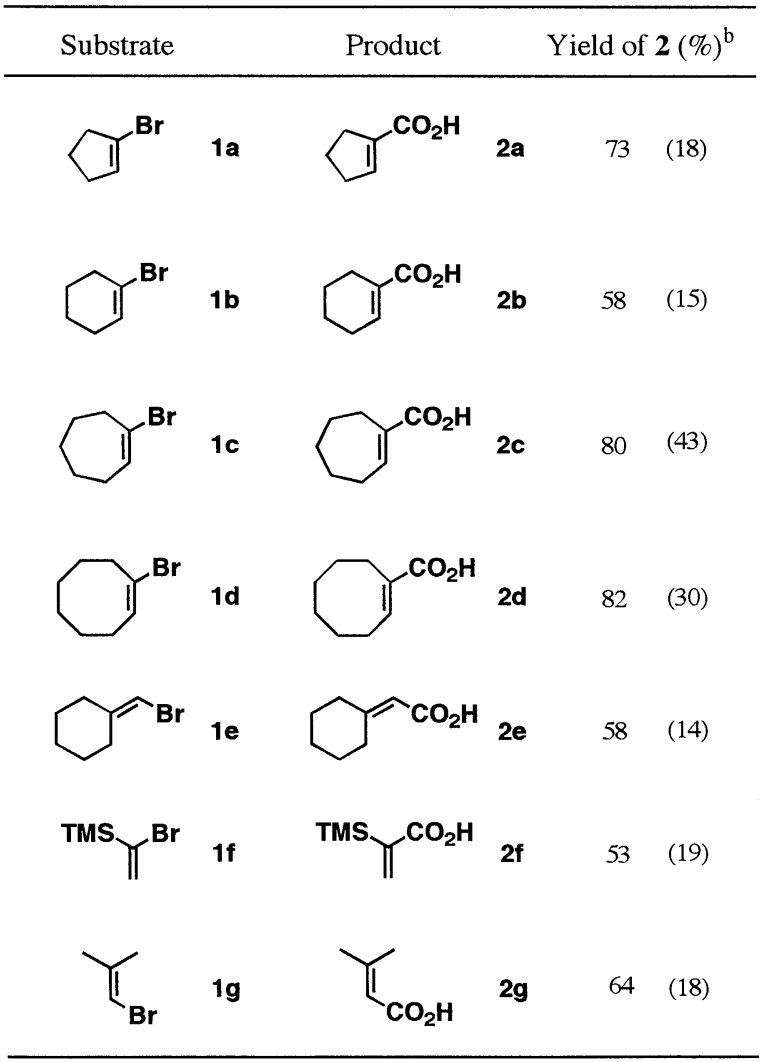

${ }^{a}$ Vinylic bromide $(3 \mathrm{mmol})$ in $0.1 \mathrm{M} \mathrm{Bu}_{4} \mathrm{NBF}_{4}-\mathrm{DMF}(15 \mathrm{ml})$ was electrolyzed in the presence of $20 \mathrm{~mol} \%$ of $\mathrm{NiBr}_{2} \bullet$ bpy under an atmospheric carbon dioxide with a Pt cathode and a $\mathrm{Mg}$ anode. ${ }^{\mathrm{b}}$ Isolated yields. Yields in the absence of a Ni complex catalyst are shown in parentheses. 
corresponding $\alpha, \beta$-unsaturated carboxylic acids (2a-2g) in isolated yields of $53-82 \%$ (Scheme 1)(Table 1). Similar electrochemical carboxylation of $\mathbf{1} \mathbf{a}-\mathbf{1} \mathbf{g}$ in the absence of Ni(II) complex gave $\mathbf{2 a - 2} \mathbf{g}$ in $14-43 \%$ yields (Table 1). $\alpha, \beta$-Unsaturated carboxylic acids such as $\mathbf{2 a - 2}$, especially acrylic acid carrying a trimethylsilyl group at the $\alpha$-position (2f), are useful intermediates in organic synthesis.

The probable reaction pathways of the present electrochemical carboxylations are shown in Scheme 2. A two-electron reduction of $\mathrm{NiBr}_{2} \bullet$ bpy gives $\mathrm{Ni}(0)$ species, and an oxidative addition of the $\mathrm{Ni}(0)$ to vinylic bromide would produce the complex $\mathbf{A} \cdot{ }^{13,14}$ A two-electron reduction of the complex $\mathbf{A}$ gives the corresponding vinyl carbanion (B), which is trapped by atmospheric carbon dioxide to give the corresponding alkenoate (C). At the anode, on the other hand, a dissolution of magnesium metal takes place to give magnesium ion. The magnesium ion readily captures 2-alkenoates $(\mathbf{C})$ to give the stable magnesium carboxylate $\mathbf{D}$ or $\mathbf{E}$. Acid treatment of $\mathbf{D}$ or $\mathbf{E}$ gives $\alpha, \beta$-unsaturated carboxylic acids $2 \mathbf{a}-2 \mathrm{~g}$. Cyclic voltammetry of $1 \mathrm{c}$ in the presence of $\mathrm{NiBr}_{2} \bullet$ bpy showed the existence of a new reduction peak at ca. $-1.5 \mathrm{~V} v s \mathrm{Ag} / \mathrm{AgCl}$, although the reduction peaks of $1 \mathrm{c}$ and $\mathrm{NiBr}_{2} \bullet$ bpy alone appeared at $<-2.6 \mathrm{~V}$ and $-1.25 \mathrm{~V}$, respectively. Detailed study on the reaction pathways of the present electrochemical carboxylation is now in progress.

at cathode $(\mathrm{Pt})$
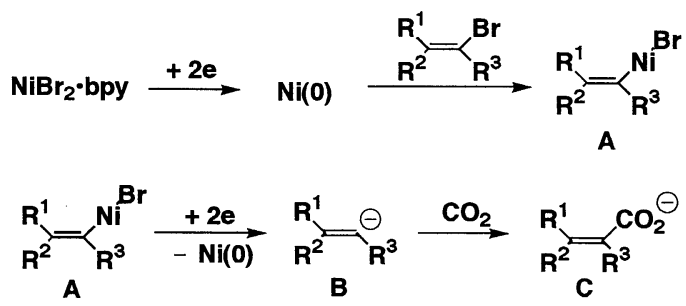

at anode $(\mathrm{Mg})$

$\mathrm{Mg} \longrightarrow \mathrm{Mg}^{2+}+2 \mathrm{e}$

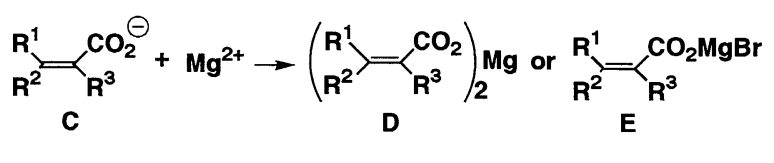

Scheme 2.
Electrochemical carboxylation of vinylic bromides 1 gave low yields of products 2 when the electrolysis was carried out in the absence of $\mathrm{Ni}$ (II) complex. It is probably due to an ineffective reduction of 1 which has negative reduction potential $(<-2.6 \mathrm{~V} v s$ $\mathrm{Ag} / \mathrm{AgCl}$ ). Apparent reduction petentials of 1 were moved to more positive ones $(-1.5 \mathrm{~V})$ by the addition of the $\mathrm{Ni}$ (II) complex, which probably resulted in increased yields of 2 .

This work was supported in part by a Grant-in-Acid for Scientific Reseach (A) (No.07555580) from The Ministry of Education, Science, Sports and Culture, and a Takeda Science Foundation.

\section{References and Notes}

1 G. Silvetsri, S. Gambino, G. Filardo, and A. Gulotta, Angew. Chem. Int. Ed. Engl., 23, 979 (1984).

2 G. Silvetsri, S. Gambino, and G. Filardo, Acta Chem. Scand., 45, 987 (1991).

3 O. Sock, M. Troupel, and J. Perichon, Tetrahedron Lett., 26,1509 (1985).

4 J. Chaussard, J. C. Folest, J. Y. Nedelec, J. Perichon, and S. Sibille, and M. Troupel, Synthesis, 369 (1990).

5 M. Tokuda, T. Kabuki, Y. Katoh, and H. Suginome, Tetrahedron Lett., 36, 3345 (1995).

6 M. Tokuda, T. Kabuki, and H. Suginome, DENKI $K A G A K U, 62,1144$ (1994).

7 M. Tokuda, A. Yoshikawa, H. Suginome, and H. Senboku, SYNTHESIS, in press (1997).

8 H. Kamekawa, H. Senboku, and M. Tokuda, Electrochimica Acta, 4 2, 2117 (1997).

9 L. Garnier, Y. Rollin, and J. Perichon, J. Organomet. Chem., 367, 347 (1989).

10 E. W. Colvin, in "Comprehensive Organic Chemistry," ed by D. Barton and W. D. Ollis, Pergamon, Oxford (1979), Vol.2, part 9, p.617.

11 1-Bromocycloalkenes $\mathbf{1 a}, \mathbf{1 b}, \mathbf{1 c}$, and $\mathbf{1 d}$ were prepared from the corresponding cycloalkenes by the brominationdehydrobromination procedure. Bromomethylenecyclohexene (1e) was prepared according to the published method. ${ }^{12}$

12 B. M. Trost, J. Dumas, and M. Villa, J. Am. Chem. Soc., 114, 9836 (1992).

13 J. F. Fauvarque, A. Jutand, and M. Francois, J. Appl. Electrochem., 18, 109 (1988).

14 S. Durandetti, S. Sibille, and J. Perichon, J. Org. Chem., 54, 2198 (1989). 